\title{
Tinjauan Kelengkapan Pengisian Rekam Medis Rawat Inap di Rumah Sakit As-Syifa Bengkulu Selatan
}

\section{Overview of Completeness of Inpatient Medical Record Filling in Hospitals As-Syifa South Bengkulu}

\author{
Amy Rahmadaniah Safitri ${ }^{1}$, Deasy Rosmala Dewi ${ }^{2}$, Noor Yulia ${ }^{3}$, Nanda Aula Rumana ${ }^{4}$ \\ Prodi Rekam Medis dan Informasi Kesehatan Universitas Esa Unggul, Jakarta, Indonesia \\ Jalan Arjuna Utara No. 9 Kebon Jeruk, Jakarta Barat - 11510 \\ *e-mail korespondensi: amyrahmadania10@gmail.com
}

\begin{abstract}
Abstrak
Rekam medis adalah berkas yang berisikan catatan dan dokumen tentang identitas pasien, pemeriksaan, pengobatan, tindakan dan pelayanan lain yang telah diberikan kepada pasien. Kelengkapan rekam medis adalah kajian atau telaah isi rekam medis berkaitan dengan pendokumentasian, pelayanan dan atau menilai kelengkapan rekam medis. Analisis kelengkapan adalah suatu review area tertentu catatan medis untuk mengidentifikasikan defisiensi spesifik. Tujuan penelitian ini adalah untuk mendapatkan gambaran mengenai kelengkapan pengisian berkas rekam medis rawat inap di Rumah Sakit As-Syifa. Metode penelitian yang digunakan dalam penelitian ini adalah metode deskriptif dengan pendekatan kuantitatif. Populasi dalam penelitian adalah rekam medis pasien rawat inap di rumah sakit As-Syifa dengan sampel 59 rekam medis, pengambilan sampel menggunakan teknik Accidental Sampling yaitu peneliti mengambil sampel yang kebetulan ditemuinya. Berdasarkan hasil perhitungan menggunakan analisis kuantitatif diperoleh rata-rata kelengkapan $84,13 \%$ dan ketidaklengkapan 15,87\%, kelengkapan tertinggi yaitu pada komponen Laporan/Catatan Yang Penting dengan persentase kelengkapan $(99,27 \%)$ dan kelengkapan terendah yaitu pada komponen Pencatatan yang baik dengan persentase kelengkapan (52\%). Berdasarkan penelitian yang telah dilakukan dapat disimpulkan bahwa pengisian rekam medis di Rumah Sakit AsSyifa belum lengkap. Hal ini dikarenakan belum adanya SPO yang mengatur tentang pengisian dan analisis kelengkapan rekam medis di rumah sakit tersebut.
\end{abstract}

Kata kunci: Kelengkapan, Rekam medis, Rumah Sakit

\begin{abstract}
Medical record is a file containing records and documents regarding patient identity, examination, treatment, actions and other services that have been provided to patients. Completeness of medical records is a study or review of the contents of medical records relating to documentation, services and or assessing the completeness of medical records. Completeness analysis is a review of a specific area of the medical record to identify specific deficiencies. The purpose of this study was to obtain an overview of the completeness of filling out inpatient medical record files at As-Syifa Hospital. The research method used in this study is a descriptive method with a quantitative approach. The population in this study is the medical records of inpatients at the As-Syifa hospital with a sample of 59 medical records, sampling using the Accidental Sampling technique, namely the researcher takes samples that he happens to meet. Based on the results of calculations using quantitative analysis obtained an average of $84.13 \%$ completeness and $15.87 \%$ incompleteness, the highest completeness is in the Important Reports/Notes component with the percentage of completeness $(99.27 \%)$ and the lowest completeness is in the Good Recording component. with the percentage of completeness $(52 \%)$. Based on the research that has been done, it can be concluded that the filling of medical records at As-Syifa Hospital is not complete. This is because there is no SOP that regulates the filling and analysis of the completeness of medical records at the hospital.
\end{abstract}

Keywords: Equipment, Medical Records, Hospital 


\section{PENDAHULUAN}

Rekam medis adalah berkas yang berisikan catatan dan dokumen tentang identitas pasien, pemeriksaan, pengobatan, tindakan dan pelayanan lain yang telah diberikan kepada pasien (Kemenkes RI 2008). Standar Pelayanan Minimal (SPM) adalah ketentuan mengenai Jenis dan Mutu Pelayanan Dasar yang merupakan Urusan Pemerintahan Wajib yang berhak diperoleh setiap Warga Negara secara minimal (Kemenkum HAM 2018). Kelengkapan rekam medis adalah kajian atau telaah isi rekam medis berkaitan dengan pendokumentasian, pelayanan dan atau menilai kelengkapan rekam medis. Analisis kelengkapan adalah suatu review area tertentu catatan medis untuk mengidentifikasikan defisiensi spesifik. Area yang ditentukan biasanya tertulis di dalam suatu prosedur yang dikembangkan bersama oleh manajer informasi kesehatan dan penyediaan layanan kesehatan sesuai dengan aturan staff medis dan kebijaksanaan administrasi dari fasilitas yang bersangkutan, dan standar dari badan-badan pemberi lisensi, akreditasi dan sertifikat (Huffman 1999). Kelengkapan pengisian rekam medis dapat dipengaruhi oleh beberapa faktor, antara lain: 1. latar belakang pendidikan tenaga kesehatan, 2. masa kerja, 3. pengetahuan mengenai rekam medis (manfaat, kegunaan, pertanggung jawaban), 4. ketrampilan, 5. motivasi, 6. alat kerja, 7. sarana kerja, 8. waktu kerja, 9. pedoman tertulis, 10. kepatuhan terhadap pedoman (Wulandari 2012). Rumah Sakit As-syifa adalah rumah sakit umum di Kota Manna Bengkulu Selatan milik swasta yang bergerak di bidang pelayanan kesehatan baik pelayanan umum maupun spesialistik. Izin operasional RS AS-SYIFA secara resmi dikeluarkan oleh Dinas Penanaman Modal dan Pelayanan Terpadu Satu Pintu kebupaten Bengkulu Selatan pada tanggal 18 Agustus 2017, efektif beroperasi mulai tanggal 1 Oktober 2017 dengan kapasitas tempat tidur 62 buah dan dilengkapi sarana dan prasarana yang dikerjakan tenaga-tenaga terampil dan professional. Dari hasil pengamatan, pada bulan November 2020 di Rumah Sakit As-Syifa Bengkulu Selatan pada bagian assembling dalam pelaksanaan tugasnya di peroleh data dokumen rekam medis rawat inap yang masih menumpuk dibagian assembling dan masih ada dokumen rekam medis yang tidak lengkap pengisiannya. Rumah Sakit yang menjadi tempat penelitian tidak memiliki SPO untuk pengisian rekam medis rawat inap dan SPO Analisis Dari hasil Analisis Kuantitatif terhadap 30 RM bulan November 2020 diperoleh hasil persentase rata-rata terisi sebanyak $90,75 \%$ dan tidak terisi sebanyak 9,25\%. Dampak dari ketidaklengkapan pengisian rekam medis adalah terhambatnya proses klaim asuransi yang diajukan dan terhambatnya proses tertib administrasi.

\section{METODE PENELITIAN}

Penelitian dilakukan secara deskriptif dengan memberikan gambaran atau mendeskripsikan tentang suatu keadaan secara objektif. Untuk mengukur kelengkapan rekam medis dan menemukan faktor-faktor yang mempengaruhi kelengkapan rekam medis rawat inap di RS As-Syifa Bengkulu Selatan. Metode pengumpulan data adalah dengan observasi, wawancara dan studi kepustakaan. Penelian dilakukan pada Mei 2021. Populasi yang digunakan adalah seluruh rekam medis rawat inap. Sampel yang digunakan sebanyak 59 rekam medis rawat inap yang ditentukan menggunakan rumus estimasi proporsi dengan teknik pengambilan secara sampel Accidental Sampling yaitu peneliti mengambil sampel yang kebetulan ditemuinya. Data yang didapatkan kemudian akan disusun, diolah, dianalisa, dan disajikan dalam bentuk laporan.

\section{HASIL DAN PEMBAHASAN}

\section{Identifikasi SPO Pengisian Rekam Medis Rawat Inap}

Berdasarkan hasil penelitian yang dilakukan rumah sakit yang menjadi tempat penelitian belum mempunyai SPO pengisian rekem medis rawat inap. SOP rekam medis diadakan agar mempermudah dalam melakukan pencatatan formulir sesuai dengan ketentuan pengisian.

\section{Analisis Kelengkapan Pengisian Rekam Medis Rawat Inap}

Penelitian ini dilakukan di Rumah Sakit AsSyifa Bengkulu Selatan pada bulan Mei 2021 dengan menggunakan sampel 59 rekam medis rawat inap. 
Tabel 1. Identifikasi Pasien

\begin{tabular}{|c|c|c|c|}
\hline \multirow[t]{2}{*}{ No } & \multirow{2}{*}{$\begin{array}{l}\text { Identitas } \\
\text { Pasien }\end{array}$} & \multicolumn{2}{|c|}{ Kelengkapan } \\
\hline & & Jumlah & Persentase \\
\hline 1 & Nama & 59 & $100 \%$ \\
\hline 2 & $\begin{array}{l}\text { Nomor Rekam } \\
\text { Medis }\end{array}$ & 59 & $100 \%$ \\
\hline 3 & $\begin{array}{l}\text { Tgl. } \\
\text { Lahir/Umur }\end{array}$ & & $100 \%$ \\
\hline \multirow[t]{2}{*}{4} & Jenis Kelamin & 56 & $95 \%$ \\
\hline & Average & 58 & $98,75 \%$ \\
\hline $\begin{array}{l}\text { men } \\
\text { dokl } \\
\text { Saki } \\
\text { med } \\
\text { dan } \\
\text { terd } \\
\text { ini } \\
\text { pent } \\
\text { reka } \\
\text { kom } \\
\text { men } \\
\text { terse } \\
\text { dokı } \\
\text { adm } \\
\text { teris } \\
\text { bera } \\
\text { iden } \\
\text { dan }\end{array}$ & $\begin{array}{l}\text { Dari has } \\
\text { njukkan unt } \\
\text { nen rekam m } \\
\text { As-Syifa Beng } \\
\text { yang diteliti } \\
1,25 \% \text { ) tidak } \\
\text { at pada butir } \\
\text { sebabkan kare } \\
\text { g dari keleng } \\
\text { medis pasie } \\
\text { onen identifik } \\
\text { astikan pemilik } \\
\text { ut. Kelengkap } \\
\text { nen rekam } \\
\text { iistratif sebaga } \\
\text { lengkap karen } \\
\text { ibat tidak } \\
\text { tas pasien seba } \\
\text { sumber peren } \\
\text { anan kesehatan }\end{array}$ & $\begin{array}{l}\text { anali } \\
\text { Revi } \\
\text { is rawat } \\
\text { ulu Selat } \\
\text { peroleh } \\
\text { ngkap. I } \\
\text { ngisian j } \\
\text { petugas } \\
\text { apan pe } \\
\text { Keleng } \\
\text { i pasien } \\
\text { ari doku } \\
\text { identifi } \\
\text { nedis } 1 \\
\text { nformasi } \\
\text { jika tid } \\
\text { apat n } \\
\text { ai basis } \mathrm{a} \\
\text { naan ru }\end{array}$ & $\begin{array}{l}\text { kuantit } \\
\text { Identifil } \\
\text { nap di Rur } \\
\text { dari } 59 \text { rek } \\
3,75 \% \text { ) leng } \\
\text { tidaklengka } \\
\text { is kelamin. } \\
\text { eelum tahu } \\
\text { isian dokur } \\
\text { apan pengi } \\
\text { ertujuan un } \\
\text { en rekam m } \\
\text { si pasien p } \\
\text { rupakan } \\
\text { lemografi ha } \\
\text { terisi leng } \\
\text { nginformasi } \\
\text { a statistik, } r \\
\text { lah sakit a }\end{array}$ \\
\hline
\end{tabular}

Tabel 2. Laporan/Catatan Yang Penting

\begin{tabular}{clcc}
\hline No & $\begin{array}{c}\text { Laporan/Catatan } \\
\text { Yang Penting }\end{array}$ & \multicolumn{2}{c}{ Kelengkapan } \\
\cline { 3 - 4 } & Jumlah & Persentase \\
\hline 1 & Surat Rujukan & - & - \\
2 & Persetujuan Umum & 59 & $100 \%$ \\
3 & Pengkajian Awal & 58 & $98 \%$ \\
& Perawat & & \\
4 & Pengkajian Awal & 59 & $100 \%$ \\
& Medis & & \\
5 & Cppt & 59 & $100 \%$ \\
6 & Ask & 59 & $100 \%$ \\
7 & Observasi Klinis & 58 & $98 \%$ \\
8 & CP & 58 & $98 \%$ \\
9 & Rencana Pasien & 58 & $98 \%$ \\
& Pulang & & \\
10 & Resume & 59 & $100 \%$ \\
& Keperawatan & & \\
11 & Ringkasan Pulang & 59 & $100 \%$ \\
12 & SPTK & 49 & $100 \%$ \\
\hline & Average & 56 & $99,27 \%$ \\
\hline
\end{tabular}

Dari hasil analisis kuantitatif menunjukkan untuk Review Laporan/catatan yang baik dokumen rekam medis rawat inap di Rumah Sakit As-Syifa Bengkulu Selatan dari 59 rekam medis yang diteliti diperoleh $(99,27 \%)$ lengkap dan $(0,73 \%)$ tidak lengkap. Persentase kelengkapan paling tinggi yaitu pada komponen persetujuan umum, pengkajian awal medis, cppt, Ask, resume keperawatan, ringkasan pulang, SPTK sebesar (100\%), sedangkan kelengkapan terendah yaitu pada komponen pengkajian awal perawat, observasi klinis, $\mathrm{CP}$, rencana pasien pulang (98\%). Hal ini disebabkan karena petugas belum tahu arti penting dari kelengkapan pengisian dokumen rekam medis pasien.

Tabel 3. Autentikasi Penulis

\begin{tabular}{|c|c|c|c|}
\hline \multirow[t]{2}{*}{ No } & \multirow{2}{*}{$\begin{array}{l}\text { Autentikasi } \\
\text { Penulis }\end{array}$} & \multicolumn{2}{|c|}{ Kelangkapan } \\
\hline & & Jumlah & Persentase \\
\hline 1 & Nama Dokter & 58 & $98 \%$ \\
\hline 2 & $\begin{array}{l}\text { Tanda Tangan } \\
\text { Dokter }\end{array}$ & 54 & $92 \%$ \\
\hline 3 & Nama Perawat & 36 & $61 \%$ \\
\hline 4 & $\begin{array}{l}\text { Tanda Tangan } \\
\text { Perawat }\end{array}$ & 56 & $95 \%$ \\
\hline & Average & 51 & $86,5 \%$ \\
\hline $\begin{array}{l}\text { ment } \\
\text { doku } \\
\text { Saki } \\
\text { medi } \\
\text { dan } \\
\text { keler } \\
\text { penu } \\
\text { pada } \\
\text { dokt } \\
\text { (95\% } \\
\text { terda } \\
\text { yang } \\
\text { bahy } \\
\text { terisi } \\
\text { terse } \\
\text { ment } \\
\text { serin }\end{array}$ & $\begin{array}{l}\text { Dari hasil } \\
\text { njukkan untuk } \\
\text { nen rekam medi } \\
\text { As-Syifa Bengku } \\
\text { yang diteliti di] } \\
13,5 \% \text { ) tidak leng } \\
\text { gkapan pengisian } \\
\text { is pada pasien ra } \\
\text { item nama dokt } \\
\text { ( } 92 \% \text { ), dan tand } \\
\text { yang terisi leng } \\
\text { at pada item nam } \\
\text { terisi lengkap. H } \\
\text { a masih banyak n } \\
\text { lengkap pada dol } \\
\text { ut dikarenakan } \\
\text { lis autentifikasi, } \\
\text { untuk tanda tang }\end{array}$ & $\begin{array}{l}\text { analisis } \\
\text { Review } \\
\text { rawat in } \\
\text { Selatan } \\
\text { eroleh ( } 86 \\
\text { ap. Perse } \\
\text { komponen } \\
\text { wat inap } \\
\text { r (98\%), } \\
\text { tangan pe } \\
\text { ap. Perser } \\
\text { perawat } \\
\text { sil tersebu } \\
\text { ma peraw } \\
\text { amen reka } \\
\text { sibukan } \mathrm{p} \\
\text { ehingga } \\
\text { n saja. }\end{array}$ & $\begin{array}{l}\text { kuantitatif } \\
\text { Autentikasi } \\
\text { p di Rumah } \\
\text { lari } 59 \text { rekam } \\
5 \% \text { ) lengkap } \\
\text { tase tertinggi } \\
\text { autentifikasi } \\
\text { aitu terdapat } \\
\text { tanda tangan } \\
\text { rawat sebesar } \\
\text { tase terendah } \\
\text { ebesar (61\%) } \\
\text { menunjukan } \\
\text { t yang belum } \\
\text { m medis. Hal } \\
\text { erawat untuk } \\
\text { erawat lebih }\end{array}$ \\
\hline \multicolumn{4}{|c|}{ Tabel 4. Catatan Yang Baik } \\
\hline \multirow[t]{2}{*}{ No } & \multirow{2}{*}{$\begin{array}{c}\text { Catatan Yang } \\
\text { Baik }\end{array}$} & \multicolumn{2}{|c|}{ Kelengkapan } \\
\hline & & Jumlah & Persentase \\
\hline 1 & $\begin{array}{l}\text { Tidak Ada } \\
\text { Coretan }\end{array}$ & 19 & $32 \%$ \\
\hline 2 & $\begin{array}{l}\text { Tidak Ada Tipe- } \\
\text { X }\end{array}$ & 54 & $92 \%$ \\
\hline 3 & Tidak Ada & 19 & $32 \%$ \\
\hline
\end{tabular}

p-ISSN: | e-ISSN: 2807-2596

website: ijhim.stikesmhk.ac.id/index.php/ 


\begin{tabular}{cccc}
\hline No & $\begin{array}{c}\text { Catatan Yang } \\
\text { Baik }\end{array}$ & \multicolumn{2}{c}{ Kelengkapan } \\
\cline { 2 - 3 } & Jumlah & Persentase \\
\hline \multicolumn{3}{c}{ Bagian Kosong } & \\
\hline Average & 31 & $52 \%$ \\
\hline Dari hasil & analisis & kuantitatif
\end{tabular}

menunjukkan untuk Review Catatan yang baik dokumen rekam medis rawat inap di Rumah Sakit As-Syifa Bengkulu Selatan dari 59 rekam medis yang diteliti diperoleh kelengkapan (52\%) dan tidak lengkap (48\%). persentase kelengkapan tertinggi yaitu pada komponen tidak ada tipe-x $(92 \%)$, sedangkan persentase terendah yaitu pada komponen tidak ada coretan (32\%) dan tidak ada bagian kosong (32\%).

Pencatatan dalam berkas rekam medis harus selalu dilakukan dengan cara yang benar karena apabila terjadi kesalahan pencatatan dalam berkas rekam medis tidak dibenarkan untuk melakukan penghapusan dengan cara apapun. Untuk mengkoreksinya adalah dengan cara bagian yang salah digaris (dicoret) namun, catatan tersebut harus masih bisa terbaca. Kemudian diberi catatan disampingnya bahwa catatan tersebut salah. Terakhir ditambahkan paraf dari petugas yang bersangkutan.

Tabel 5. Rekapitulasi Pengolahan Data Analisis Kuantitatif Komponen 1-4

\begin{tabular}{|c|c|c|c|c|}
\hline $\begin{array}{c}\text { Komponen } \\
\text { Pengisian } \\
\text { Rekam } \\
\text { Medis }\end{array}$ & $\begin{array}{c}\text { Leng } \\
\text { kap }\end{array}$ & $\begin{array}{c}\text { Pers } \\
\text { en }\end{array}$ & $\begin{array}{c}\text { Tidak } \\
\text { Lengk } \\
\text { ap }\end{array}$ & $\begin{array}{c}\text { Pers } \\
\text { en }\end{array}$ \\
\hline $\begin{array}{l}\text { Identitas } \\
\text { Pasien }\end{array}$ & 58 & $\begin{array}{l}98,7 \\
5 \%\end{array}$ & 1 & $\begin{array}{c}1,25 \\
\%\end{array}$ \\
\hline $\begin{array}{l}\text { Laporan/Cat } \\
\text { atan Yang } \\
\text { Penting }\end{array}$ & 56 & $\begin{array}{l}99,2 \\
7 \%\end{array}$ & 3 & $\begin{array}{c}0,73 \\
\%\end{array}$ \\
\hline $\begin{array}{l}\text { Autentifikasi } \\
\text { Penulis }\end{array}$ & 51 & $\begin{array}{c}86,5 \\
\%\end{array}$ & 8 & $\begin{array}{c}13,5 \\
\%\end{array}$ \\
\hline $\begin{array}{l}\text { Pencatatan } \\
\text { Yang Baik }\end{array}$ & 31 & $52 \%$ & 28 & $48 \%$ \\
\hline Average & 49 & $\begin{array}{l}84,1 \\
3 \%\end{array}$ & 10 & $\begin{array}{c}15,8 \\
7 \%\end{array}$ \\
\hline
\end{tabular}

Berdasarkan rekapitulasi pengelolaan data analisis kuantitatif rekam medis yang dilakukan oleh peneliti di Rumah Sakit As-Syifa pada Pada bulan Mei 2021 dengan menggunakan 59 sampel berkas rekam medis rawat inap dari hasil penelitian tersebut masih ditemukan berkas rekam medis rawat inap yang pengisian dan penulisannya tidak lengkap dengan persentase rata-rata kelengkapan sebesar 84,13\% dan tidak lengkapan 15,87\%. Kelengkapan tertinggi yaitu pada komponen Laporan/Catatan Yang Penting dengan persentase kelengkapan $(99,27 \%)$ dan kelengkapan terendah yaitu pada komponen Pencatatan yang baik dengan persentase kelengkapan (52\%). Hal ini belum sesuai dengan Peraturan Mentri Kesehatan Republik Indonesia tentang Standar Pelayanan Minimal Rumah Sakit yang menyebutkan bahwa kelengkapan pengisisan rekam medis $100 \%$ setelah selesai pelayanan.

\section{Faktor Penyebab Ketidaklengkapan Pengisian Rekam Medis Rawat Inap.}

\section{Sumber Daya Manusia (SDM)}

Dilihat dari pengetahuan, masih ada petugas kesehatan yang belum mengetahui bahwa rekam medis harus segera dilengkapi $<24$ jam saat pasien telah dinyatakan pulang. Pengetahuan akan kelengkapan rekam medis sangat penting bagi petugas kesehatan baik itu dokter, perawat terutama petugas rekam medis. Pengetahuan yang tinggi terhadap kegunaan rekam medis akan membuat petugas lebih memperhatikan kelengkapan rekam medis. Penyebab lain ketidaklengkapan rekam medis adalah dokter dan perawat yang kurang disiplin dalam melakukan pengisian rekam medis termasuk petugas kesehatan yang telat mengembalikan dokumen rekam medis ke petugas rekam medis lebih dari $2 \times 24$ jam. Faktor lain adalah kurangnya kesadaran dokter akan pentingnya kelengkapan pengisian berkas rekam medis dan ketidakdisiplinan dokter yang bertanggungjawab merawat pasien. Kesibukan dijadikan alasan utama dokter tidak melengkapi pengisian rekam medis namun seharusnya kesibukan itu tidak dijadikan alasan karena membuat rekam medis dan melengkapi rekam medis dalah kewajiban seorang dokter. Hal ini sejalan seperti yang dijelaskan UU Praktik Kedokteran yang menyatakan bahwa dokter dalam menjalankan praktik kedokterannya wajib membuat rekam medis.

Dilihat dari segi motivasi, ternyata masih banyak petugas yang kurang memiliki kesadaran terhadap dampak ketidaklengkapan rekam medis, manfaat dan kegunaan rekam medis serta kurangnya perilaku petugas untuk mengingat dokter agar melengkapi dokumen rekam medis pasien. Memacu motivasi pegawai harus dilakukan untuk mendorong pencapaian kinerja yang baik. Motivasi merupakan proses pemberian motif kepada para pegawai sehingga mereka mau bekerja demi tercapainya tujuan 
perusahaan secara efektif dan efisien (Murti dkk., 2013).

\begin{abstract}
Alat
Sarana dan prasarana merupakan suatu alat yang digunakan untuk mencetak keberhasilan suatu instansi berdasarkan data yang didapatkan. Dilihat dari segi alat, penyebanya adalah tidak adanya checklist ketidaklengkapan rekam medis, kelengkapan pengisian rekam medis merupakan hal yang perlu diperhatikan karena rekam medis berperan penting dalam menjamin keberlangsungan pelayanan medis hal ini dapat menyebabkan dampak internal dan eksternal karena hasil pengolahan data menjadi dasar pembuatan laporan yang baik. Pembuatan laporan tersebut berkaitan dengan penyusunan berbagai perencanaan rumah sakit, pengambilan keputusan oleh pimpinan khususnya dalam evaluasi pelayanan yang diberikan dengan harapan dapat menjadi lebih baik. Selain itu kelengkapan rekam medis menjadi syarat utama dalam pengajuan pengklaiman dana asuransi di rumah sakit ke BPJS, apabila resume medis tidak lengkap dapat menyebabkan penolakan oleh verifikator BPJS sehingga berkas klaim harus dikembalikan kepada rumah sakit agar segera dilengkapi. Maka dari itu kelengkapan dokumen rekam medis menjadi faktor utama untuk meningkatkan mutu pelayanan kesehatan diharapkan di rumah sakit dapat meminimalkan penurunan kualitas dari rumah sakit. Sebaiknya dalam upaya pelayanan kesehatan lebih ditingkatkan dengan cara diadakan sosialisasi terhadap standar operasional prosedur tentang kelengkapan dokumen rekam medis guna meningkatkan suatu kinerja petugas untuk melaksanakan pelayanan kesehatan sesuai dengan peraturannya.
\end{abstract}

\section{Metode}

Dari segi metode, penyebabnya adalah masih adanya rumah sakit yang belum memiliki panduan, SOP dan kebijakan di bagian rekam medis, sosialisasi SOP rekam medis yang belum optimal, tidak adanya monitoring dan evaluasi, alur rekam medis yang tidak sesuai standar dan tidak adanya sistem reward dan punishment. Hal ini mengakibatkan tidak adanya acuan bagi petugas terkait dalam melakukan pengisian rekam medis sehingga menimbulkan perbedaan persepsi tentang kelengkapan rekam medis. Kebijakan, pedoman/ panduan dan prosedur merupakan kelompok dokumen sebagai acuan melaksanakan kegiatan. Sistem monitoring dan evaluasi juga turut mempengaruhi ketidaklengkapan pengisian rekam medis. Tidak adanya sistem monitoring dan evaluasi ketidaklengkapan rekam medis menyebabkan tidak adanya pengendalian terhadap kelengkapan isi rekam medis (Mawarni dkk., 2020). Akar permasalahannya karena tidak adanya tim monitoring dan evaluasi rekam medis dan tidak adanya pencatatan dan pelaporan ketidaklengkapan dokumen rekam medis. Perlu adanya tim supervisi kelengkapan dan penyediaan catatan ketidaklengkapan dokumen rekam medis. Supervisi dapat dilakukan secara menyeluruh tidak hanya kepada dokter namun juga kepada perawat juga yang dapat berfungsi sebagai pengingat dokter dalam melakukan pengisian rekam medis.

\section{SIMPULAN}

Berdasarkan penelitian yang telah dilakukan dapat disimpulkan bahwa berdasarkan hasil penelitian rumah sakit yang menjadi tempat penelitan belum mempunyai SPO pengisian rekam medis rawat inap. Berdasarkan hasil perhitungan analisis kelengkapan rekam medis rawat inap yang dilakukan diperoleh persentase rata-rata kelengkapan sebesar $84,13 \%$ dan tidak lengkapan 15,87\%. Berdasarkan hasil penelitian faktor penyebab ketidaklengkapan pengisian rekam medis rawat inap yaitu, masih ada petugas kesehatan yang belum mengetahui bahwa rekam medis harus segera dilengkapi <24 jam saat pasien telah dinyatakan pulang, tidak adanya catatan/ checklist/data ketidaklengkapan dokumen rekam medis, dan belum adanya panduan/kebijakan/SPO untuk pengisian rekam medis rawat inap.

\section{DAFTAR RUJUKAN}

Huffman, Edna k. 1999. "Health Inforekam Medisation Management. 10th Physcitian Record Company. Berwyn, Illionis."

Kemenkum HAM. 2018. "Peraturan Pemerintah RI No 2 Tahun 2018." Sekratariat Negara RI 1-35.

Mawarni, Dian, and Ratna Dwi Wulandari. 2020. "Identifikasi Ketidak Lengkapan Rekam Medis Pasien Rawat Inap.” Jurnal 
Administrasi Kesehatan Indonesia 1(2):91-98.

Murti, Harry, and Veronika Agustini Srimulyani. 2013. "Pengaruh Motivasi Terhadap Kinerja Pegawai Dengan Variabel Pemediasi Kepuasaan Kerja Pada Pdam Kota Madiun.” JRMA Jurnal Riset Manajemen Dan Akuntansi 1(1):1017.

RI, Depkes. 2008. "Permenkes Ri 269/MENKES/PER/III/2008.” Permenkes Ri No 269/Menkes/Per/Iii/2008 2008:7.

Wulandari, Anggun Desi. 2012. "Program Pendidikan Sarjana Kedokteran Universitas Diponegoro Tahun 2011.” Program Pendidikan Sarjana Kedokteran Fakultas Kedokteran Universitas Diponegoro 1-18. 